\title{
A new classification of Diabetic Nephropathy 2014: a report from Joint Committee on Diabetic Nephropathy
}

\author{
Masakazu Haneda $\cdot$ Kazunori Utsunomiya $\cdot$ Daisuke Koya $\cdot$ Tetsuya Babazono $\cdot$ Tatsumi Moriya \\ Hirofumi Makino $\cdot$ Kenjiro Kimura $\cdot$ Yoshiki Suzuki $\cdot$ Takashi Wada $\cdot$ Susumu Ogawa $\cdot$ Masaaki Inaba \\ Yoshihiko Kanno - Takashi Shigematsu - Ikuto Masakane $\cdot$ Ken Tsuchiya Keiko Honda Kazuko Ichikawa • \\ Kenichiro Shide
}

Published online: 20 December 2014

(c) Japanese Society of Nephrology, The Japan Diabetes Society, The Japanese Society for Dialysis Therapy, and Japan Society of Metabolism and Clinical Nutrition 2014

\begin{abstract}
The Joint Committee on Diabetic Nephropathy has revised its Classification of Diabetic Nephropathy (Classification of Diabetic Nephropathy 2014) in line with the widespread use of key concepts such as the estimated glomerular filtration rate (eGFR) and chronic kidney disease. In revising the Classification, the Committee carefully evaluated, as relevant to current revision, the report of a study conducted by the Research Group of Diabetic
\end{abstract}

Japan Diabetes Society, Japanese Society of Nephrology, Japanese Society for Dialysis Therapy, and Japan Society of Metabolism and Clinical Nutrition established the Joint Committee on Diabetic Nephropathy, which published the revised Classification of Diabetic Nephropathy 2014 in Japanese [1-4]. This is the English version of that revision.

This article has been jointly published in Diabetology International (doi:10.1007/s13340-014-0197-4) by the Japan Diabetes Society and Clinical and Experimental Nephrology by Japanese Society of Nephrology.

The following authors are members of Japan Diabetes Society: Masakazu Haneda, Kazunori Utsunomiya, Daisuke Koya, Tetsuya Babazono, Tatsumi Moriya.

The following authors are members of Japanese Society of Nephrology: Hirofumi Makino, Kenjiro Kimura, Yoshiki Suzuki, Takashi Wada, Susumu Ogawa.

The following authors are members of Japanese Society for Dialysis Therapy: Masaaki Inaba, Yoshihiko Kanno, Takashi Shigematsu,

Ikuto Masakane, Ken Tsuchiya.

The following authors are members of Japan Society of Metabolism and Clinical Nutrition: Keiko Honda, Kazuko Ichikawa, Kenichiro Shide.

\section{Haneda}

Division of Metabolism and Biosystemic Science, Department of Medicine, Asahikawa Medical University,

1-1-1 Higashi-Nijyo, Midorigaoka, Asahikawa,

Hokkaido 078-8510, Japan
Nephropathy, Ministry of Health, Labour and Welfare of Japan. Major revisions to the Classification are summarized as follows: (1) eGFR is substituted for GFR in the Classification; (2) the subdivisions A and B in stage 3 (overt nephropathy) have been reintegrated; (3) stage 4 (kidney failure) has been redefined as a GFR less than $30 \mathrm{~mL} / \mathrm{min} /$ $1.73 \mathrm{~m}^{2}$, regardless of the extent of albuminuria; and (4) stress has been placed on the differential diagnosis of diabetic nephropathy versus non-diabetic kidney disease as being crucial in all stages of diabetic nephropathy.

Keywords Diabetic nephropathy - Chronic kidney disease (CKD) - Albuminuria · Proteinuria · Glomerular filtration rate (GFR)

\section{Introduction}

Diabetic nephropathy became the leading cause of chronic dialysis in 1998. Since then, the incidence of this condition has increased with only a recent plateau. However, diabetic nephropathy continues to account for a large proportion of all cases of chronic kidney disease (CKD) and remains by far the most common underlying cause of chronic dialysis among all kidney diseases [5], consequently leading to the escalation of healthcare costs, thus representing a compelling medico-social issue of interest.

The Classification of Diabetic Nephropathy (hereafter "Classification") developed earlier by the Research Group

\section{K. Utsunomiya}

Division of Diabetes, Endocrinology and Metabolism,

Department of Internal Medicine, Jikei University School of Medicine, 3-25-8 Nishi-shinbashi, Minato-ku, Tokyo 105-8461, Japan 
of Diabetic Nephropathy at the Ministry of Health, Labour and Welfare (MHLW) [6] and later revised by the Joint Committee on Diabetic Nephropathy (hereafter "Committee") [7] is widely used in Japan. However, as the concept of CKD was proposed, followed by the classification of CKD stages [8], it became clear that there exists a subpopulation of patients with discrepant classifications of diabetic nephropathy and CKD. This is thought to be due to the fact that diabetic nephropathy is primarily classified according to the extent of albuminuria in addition to the glomerular filtration rate (GFR) (i.e., creatinine clearance $[\mathrm{CCr}]$ ), whereas CKD is primarily classified based on the estimated GFR [estimated GFR (eGFR)]. Meanwhile, eGFR has become increasingly used to assess GFR, and a new classification of CKD was developed in 2012 [9]. Against this background, the Committee therefore discussed issues of interest in depth and sought to develop a revision of the Classification.

\section{Development of the 2014 Classification (Revised Classification) (see Table 1)}

Prior to revising the Classification, as part of a MHLWsubsidized project on kidney disease, entitled "Diabetic Nephropathy Research, from the Ministry of Health, Labour and Welfare of Japan", a "historical cohort study" was conducted by the Research Group of Diabetic Nephropathy, MHLW, involving a total of 4,355 subjects

\section{Koya}

Department of Diabetology and Endocrinology, Kanazawa Medical University, 1-1 Uchinadamachi-daigaku, Kahoku-gun, Ishikawa 920-0293, Japan

\section{T. Babazono}

Department of Medicine, Diabetes Center, Tokyo Women's Medical University, 8-1 Kawada-cho, Shinjuku-Ku,

Tokyo 162-8666, Japan

\section{T. Moriya}

Health Care Center, Kitasato University, 1-15-1 Kitasato,

Minami-ku, Sagamihara, Kanagawa 252-0374, Japan

\section{H. Makino ( $\square)$}

Okayama University Hospital, 2-5-1 Shikada-machi, Kita-ku, Okayama, Okayama 700-8558, Japan

e-mail: makino@md.okayama-u.ac.jp

\section{K. Kimura}

Division of Nephrology and Hypertension, Department of Internal Medicine, St. Marianna University School of Medicine, 2-16-1 Sugao, Miyamae-ku, Kawasaki, Kanagawa 216-8511, Japan

\section{Y. Suzuki}

Health Administration Center, Niigata University, 2-8085

Igarashi, Nishi-ku, Niigata, Niigata 950-2181, Japan with type 2 diabetes from 10 participating healthcare facilities with the aim of evaluating renal events (i.e., a decrease in eGFR to half the baseline level and/or the need for dialysis), cardiovascular events and all-cause mortality $[10,11]$. Summarized below are the major findings of this study (for detailed information, please access the MHLW website http://www.mhlw.go.jp/ or refer to the literature cited above).

1. Renal and cardiovascular events and all-cause mortality were significantly increased in the subjects with micro- or macroalbuminuria compared to that observed in the subjects with normoalbuminuria.

2. In those with renal impairment (defined as a GFR less than $60 \mathrm{~mL} / \mathrm{min} / 1.73 \mathrm{~m}^{2}$ ):

a. The risk of renal events increased in association with the onset of microalbuminuria and further increased with the onset of macroalbuminuria in the subjects;

b. The risk of cardiovascular events was increased in those with micro-/macroalbuminuria; and

c. All-cause mortality was increased in the subjects with macroalbuminuria as well as those with normoalbuminuria and microalbuminuria who exhibited a GFR of less than $30 \mathrm{~mL} / \mathrm{min} / 1.73 \mathrm{~m}^{2}$.

While that study was not a true prospective study and involved only a limited number of facilities and patients from a population known to be less prone to cardiovascular

\section{T. Wada}

Division of Nephrology, Department of Laboratory Medicine, Kanazawa University, 13-1 Takara-machi, Kanazawa, Ishikawa 920-8641, Japan

S. Ogawa

Center for the Advancement of Higher Education, Tohoku

University, Sendai, Japan

S. Ogawa

Division of Nephrology, Endocrinology and Vascular Medicine, Tohoku University Hospital, 1-1 Seiryou-cho, Aoba-ku, Sendai, Miyagi 980-8574, Japan

M. Inaba

Department of Metabolism, Endocrinology, Molecular Medicine, Faculty of Medicine, Osaka City University Graduate School of Medicine, 1-4-3 Asahi-cho, Abeno-ku, Osaka, Osaka 545-8585, Japan

Y. Kanno

Department of Nephrology, Tokyo Medical University, 6-7-1 Nishi-shinjuku, Shinjuku-Ku, Tokyo 160-0023, Japan

T. Shigematsu

Division of Nephrology, Department of Internal Medicine, Wakayama Medical University, 811-1 Kimiidera, Wakayama, Wakayama 641-8509, Japan 
events than those in Western countries, the findings provide important insight into the prognosis of diabetic nephropathy in Japanese patients. Therefore, in seeking to revise the Classification, the Committee gave due consideration to the above findings. At the same time, the following considerations were also taken into account.

1. The bulk of evidence for the classification of diabetic nephropathy comes from randomized controlled studies enrolling patients with diabetic nephropathy as defined based on the extent of albuminuria, and very little evidence is available for diabetic nephropathy as defined based on GFR.

2. The current "Medical Service Fee Schedule for Guidance on Preventing Diabetes-Associated Dialysis" was developed with the Classification in mind.

3. The "Guidelines for Clinical Efficacy Evaluation of Pharmacological Agents for Diabetic Nephropathy (Draft)" currently in use were developed with the Classification in mind.

Therefore, after giving due consideration to all of these issues during the course of several sessions, the Committee decided to leave the Classification essentially unchanged for now (Table 1), while showing how it may be aligned with the widespread CKD classification based on GFR (eGFR) ("see Appendix"). The former is not, however, presented as a heat map, due to the limitations of the study referred to above, which involved a small number of patients with diabetic nephropathy and included no dialysis patients, providing the basis for this revision. Again, as all kidney diseases affecting patients with diabetes are covered in the Classification, the Committee called for attention with notes included which were required, in order to highlight the importance of the differential diagnosis

I. Masakane

Department of Nephrology, Yabuki Hospital, 4-5-5 Shimakita, Yamagata, Yamagata 990-0885, Japan

K. Tsuchiya

Department of Internal Medicine IV, Tokyo Women's Medical

University, 8-1 Kawada-cho, Shinjuku-Ku, Tokyo 162-8666, Japan

\section{K. Honda}

Division of Medicine/Nutrition, Department of Applied Nutrition, Kagawa Nutrition University, 3-9-21 Chiyoda, Sakado, Saitama 350-0288, Japan

K. Ichikawa

Department of Nutrition, Kawasaki Medical School Hospital, 577 Matsushima, Kurashiki, Hiroshima 701-0192, Japan

K. Shide

Department of Metabolism and Clinical Nutrition, Kyoto University Hospital, 54 Shogoinkawara-cho, Sakyo-ku, Kyoto, Kyoto 606-8507, Japan
Table 1 Classification of Diabetic Nephropathy 2014

\begin{tabular}{|c|c|c|}
\hline Stage & $\begin{array}{l}\text { Urinary albumin }(\mathrm{mg} / \mathrm{g} \mathrm{Cr}) \text { or } \\
\text { urinary protein }(\mathrm{g} / \mathrm{g} \mathrm{Cr})\end{array}$ & $\begin{array}{l}\text { GFR (eGFR) } \\
(\mathrm{mL} / \mathrm{min} / \\
\left.1.73 \mathrm{~m}^{2}\right)\end{array}$ \\
\hline $\begin{array}{l}\text { Stage } 1 \text { (pre- } \\
\text { nephropathy) }\end{array}$ & Normoalbuminuria $(<30)$ & $\geq 30^{\mathrm{a}}$ \\
\hline $\begin{array}{l}\text { Stage } 2 \\
\text { (incipient } \\
\text { nephropathy) }\end{array}$ & Microalbuminuria $(30-299)^{\mathrm{b}}$ & $\geq 30$ \\
\hline $\begin{array}{l}\text { Stage } 3 \text { (overt } \\
\text { nephropathy) }\end{array}$ & $\begin{array}{l}\text { Macroalbuminuria }(\geq 300) \text { or } \\
\text { Persistent proteinuria }(\geq 0.5)\end{array}$ & $\geq 30^{\mathrm{c}}$ \\
\hline $\begin{array}{l}\text { Stage } 4 \text { (kidney } \\
\text { failure) }\end{array}$ & $\begin{array}{l}\text { Any albuminuria/proteinuria } \\
\text { status }^{\mathrm{d}}\end{array}$ & $<30$ \\
\hline $\begin{array}{l}\text { Stage } 5 \text { (dialysis } \\
\text { therapy) }\end{array}$ & $\begin{array}{l}\text { Any status on continued } \\
\text { dialysis therapy }\end{array}$ & \\
\hline
\end{tabular}

Diabetic nephropathy does not always progress from one stage to the next. The revised classification takes into account findings on the prognosis of type 2 diabetic patients from a "historical cohort study" conducted as part of the MHLW-subsidized Project on Kidney Disease, entitled "Diabetic Nephropathy Research, from the Ministry of Health, Labour and Welfare of Japan" [10, 11]

a While a GFR of less than $60 \mathrm{~mL} / \mathrm{min} / 1.73 \mathrm{~m}^{2}$ is consistent with the diagnosis of CKD, underlying causes other than diabetic nephropathy may be involved in patients with a GFR below $60 \mathrm{~mL} / \mathrm{min} / 1.73 \mathrm{~m}^{2}$ thus calling for the differential diagnosis between diabetic nephropathy and any other potential non-diabetic kidney diseases

b Patients with microalbuminuria are to be diagnosed as incipient nephropathy after the differential diagnosis based on the criteria for an early diagnosis of diabetic nephropathy

c Precautions are required in patients with macroalbuminuria, in whom renal events (e.g., a decrease in eGFR to half its baseline value, the need for dialysis) have been shown to increase as the GFR decreases below $60 \mathrm{~mL} / \mathrm{min} / 1.73 \mathrm{~m}^{2}$

d All patients with a GFR of less than $30 \mathrm{~mL} / \mathrm{min} / 1.73 \mathrm{~m}^{2}$ are classified as exhibiting kidney failure, regardless of their urinary albumin/ protein values. However, in those with normoalbuminuria and microalbuminuria, the differential diagnosis is required between diabetic nephropathy and any other potential non-diabetic kidney diseases

Key Precautions in View of Drug Use: This table is intended, first and foremost, as a classification of diabetic nephropathy and not as a guide to drug use. All drugs, including anti-diabetic drugs, particularly renally metabolized agents, are to be used in accordance with their prescribing information, with due consideration to relevant factors such as GFR in each patient

between diabetic nephropathy and non-diabetic kidney disease in all stages. The differential diagnosis calls for collaboration with nephrologists; such collaboration is not limited to cases requiring a renal biopsy. Furthermore, given that the disease may not always progress in some patients, numerous notes were included in the table in order to call attention to these cases. Additionally, in view of the potential need to use multiple anti-diabetic drugs over time, "Key Precautions in View of Drug Use" are included below the table. The major revisions to the Classification are summarized below:

1. eGFR is now substituted for GFR in the Classification. 
2. The stages used in the Classification have been simplified to include normoalbuminuria, microalbuminuria, macroalbuminuria and kidney failure.

3. The division between $\mathrm{A}$ and $\mathrm{B}$ (early versus late macroalbuminuria) in stage 3 has been abandoned and $A$ and $B$ have been reintegrated, due to the paucity of evidence for proteinuria of $1 \mathrm{~g}$ /day as the threshold for dividing the stage.

4. Kidney failure has been redefined in all cases as a GFR less than $30 \mathrm{~mL} / \mathrm{min} / 1.73 \mathrm{~m}^{2}$, which represents the threshold value for kidney failure obtained by quantifying the existing definition of kidney failure in the Classification based on the Classification of the Japanese Society of Nephrology (JSN) [12] with all other pre-kidney failure conditions redefined as a GFR of $30 \mathrm{~mL} / \mathrm{min} / 1.73 \mathrm{~m}^{2}$ or greater.

5. Qualifying or illustrating phases in parentheses, such as "e.g., incipient nephropathy", have been retained throughout the Classification, as they have become common currency in the field, although their removal from the Classification was suggested during the process of revision.

6. Stress is now placed on the differential diagnosis of diabetic nephropathy versus non-diabetic kidney disease as being crucial in all stages of diabetic nephropathy.

Of note, the American Diabetes Association (ADA) proposed in its Clinical Practice Recommendations 2013 that all cases of albuminuria of $30 \mu \mathrm{g} / \mathrm{mg} \mathrm{Cr}(=\mathrm{mg} / \mathrm{g} \mathrm{Cr})$ be defined as "increased urinary albumin excretion", thus abandoning the division between micro- and macroalbuminuria [13]. Again, while this concept was retained in the Clinical Practice Recommendations 2014, the ADA further proposed that microalbuminuria and macroalbuminuria be redefined as persistent albuminuria of 30-299 $\mathrm{mg} / 24 \mathrm{~h}$ and $\geq 300 \mathrm{mg} / 24 \mathrm{~h}$, respectively [14]. While this change may result in the terms micro- and macroalbuminuria ceasing to be common currency in the clinical setting in the US, to avoid confusion, the Committee has chosen not to follow suit and rather err on the side of caution, thereby retaining these terms in the Classification, given that they are less likely to no longer be used in scientific publications and are expected to remain common currency in Japan.

Last but not least, with a number of multicenter prospective studies currently underway, including the Japan Diabetes Complication and Prevention prospective (JDCP) study, JSN registries, Japan Diabetes Clinical Data Management (JDDM) studies and Japan Diabetes Optimal Integrated Treatment for 3 Major Risk Factors of Cardiovascular Diseases (J-DOIT3) randomized study, the Committee also plans to further revise the Classification in a timely fashion as required, as relevant evidence becomes available from these and other studies.

\section{Conclusions}

In order to resolve the discrepancy between the existing Classification of Diabetic Nephropathy and the current Classification of CKD stages, the Joint Committee on Diabetic Nephropathy revised its Classification of Diabetic Nephropathy. The new classification has already been uploaded onto the website of each member society represented on the Joint Committee as of January 10, 2014. Again, in view of further revisions in the years to come, the Joint Committee has termed the revised classification as the "Classification of Diabetic Nephropathy 2014."

Acknowledgments The Joint Committee on Diabetic Nephropathy would like to extend its heartfelt thanks to all investigators in the Research Group of Diabetic Nephropathy, Ministry of Health, Labour and Welfare of Japan for their contributions, which provided the basis for the current revision.

Conflict of interest Masakazu Haneda has received speaker honoraria from pharmaceutical companies Boehringer Ingelheim $\mathrm{GmbH}$, Mitsubishi Tanabe Pharma Corporation, Novo Nordisk Pharma Ltd., Daiichi-Sankyo Co., Ltd., Taisho Pharmaceutical Co., Ltd., Sanofi K.K., Merck Sharp \& Dohme, Astellas Pharma Inc., Kyowa Hakko Kirin Co., Ltd., Kowa Pharmaceutical Co., Ltd., Takeda Pharmaceutical Co., Ltd., and Novartis Pharma K.K., scholarship grants from Astellas Pharma Inc., Daiichi-Sankyo Co., Ltd., Mitsubishi Tanabe Pharma Corporation, Takeda Pharmaceutical Co., Ltd., Novo Nordisk Pharma Ltd., Merck Sharp \& Dohme, Boehringer Ingelheim $\mathrm{GmbH}$, and Eli Lilly and Company; Daisuke Koya has received speaker honoraria from pharmaceutical companies Mitsubishi Tanabe Pharma Corporation, Boehringer Ingelheim $\mathrm{GmbH}$, and Eli Lilly and Company, research grants from Mitsubishi Tanabe Pharma Corporation, Boehringer Ingelheim GmbH, Japan Tabacco Inc., Eli Lilly and Company, and Ono Pharmaceutical Co., Ltd.; Tetsuya Babazono has received speaker honoraria from pharmaceutical company Merck Sharp \& Dohme; Tatsumi Moriya has received travel expenses from pharmaceutical companies Astellas Pharma Inc., Takeda Pharmaceutical Co., Ltd., Novo Nordisk Pharma Ltd., and Daiichi-Sankyo Co., Ltd.; Hirofumi Makino has received speaker honoraria from pharmaceutical companies Teijin Pharma Limited, Chugai Pharmaceutical Co., Ltd., AbbVie GK, Astellas Pharma Inc., Boehringer Ingelheim GmbH, Daiichi-Sankyo Co., Ltd., Sumitomo Dainippon Pharma Co., Ltd., Kyowa Hakko Kirin Co., Ltd., Merck Sharp \& Dohme, Novartis Pharma K.K., Pfizer Japan Inc., Takeda Pharmaceutical Co., and Mitsubishi Tanabe Pharma Corporation, research grants from Project for accelerating Practice and Research on Community Medicine in Okayama Prefecture, scholarship grants from Astellas Pharma Inc., DaiichiSankyo Co., Ltd., Kyowa Hakko Kirin Co., Ltd., Merck Sharp \& Dohme, Takeda Pharmaceutical Co., Ltd., Mochida Pharmaceutical Co., Ltd., Novo Nordisk Pharma Ltd., and Mitsubishi Tanabe Pharma Corporation; Kenjiro Kimura has received research grants from pharmaceutical companies Otsuka Pharmaceutical Co., Ltd., Takeda Pharmaceutical Co., Ltd., Teijin Pharma Limited, Boehringer Ingelheim $\mathrm{GmbH}$, Baxter International Inc., and Sekisui Medical Co., Ltd.; Takashi Wada has received speaker honoraria from pharmaceutical company Daiichi-Sankyo Co., Ltd., scholarship grants from Chugai pharmaceutical Co., Ltd.; Susumu Ogawa has received speaker honoraria from pharmaceutical companies DaiichiSankyo Co., Ltd., Eli Lilly and Company, and Novo Nordisk 
Pharma Ltd., research grants from Daiichi-Sankyo Co., Ltd.; Masaaki Inaba has received speaker honoraria from pharmaceutical companies Bayer Yakuhin, Ltd., Takeda Pharmaceutical Co., Ltd., Merck Sharp \& Dohme, Kyowa Hakko Kirin Co., Ltd., and Asahi Kasei Pharma Corporation, research grants from Bayer Yakuhin, Ltd., Kyowa Hakko Kirin Co., Ltd., and Eli Lilly and Company; Yoshihiko Kanno has received scholarship grants from pharmaceutical company Chugai Pharmaceutical Co., Ltd., travel expenses from Abbott Japan Co., Ltd.; Takashi Shigematsu has received research grants from pharmaceutical company Bayer Yakuhin, Ltd.; Kazunori Utsunomiya, Yoshiki Suzuki, Ikuto Masakane, Ken Tsuchiya, Keiko Honda, Kazuko Ichikawa, and Kenichiro Shide have no conflict of interest.
Human rights statement and Informed consent This article does not contain any studies with human or animal subjects performed by the any of the authors.

\section{Appendix}

Relationship between the 2014 categories for diabetic nephropathy stages and the CKD severity categories

\begin{tabular}{|c|c|c|c|c|}
\hline & Albuminuria category & A1 & $\mathrm{A} 2$ & $\mathrm{~A} 3$ \\
\hline & $\begin{array}{l}\text { Quantitative urinary albumin estimation } \\
\text { Urinary albumin } / \mathrm{Cr} \text { ratio }(\mathrm{mg} / \mathrm{g} \mathrm{Cr} \text { ) } \\
\text { (quantitative urinary protein estimation) } \\
\text { (urinary protein } / \mathrm{Cr} \text { ratio }(\mathrm{g} / \mathrm{g} \mathrm{Cr} \text { ) }\end{array}$ & $\begin{array}{c}\text { Normoalbuminuria } \\
<30\end{array}$ & $\begin{array}{l}\text { Microalbuminuria } \\
\text { 30-299 }\end{array}$ & $\begin{array}{c}\text { Macroalbuminuria } \\
\geq 300 \\
\text { (or increased proteinuria) } \\
(\geq 0.50)\end{array}$ \\
\hline \multirow[t]{3}{*}{$\begin{array}{c}\text { GFR category } \\
\left(\mathrm{mL} / \mathrm{min} / 1.73 \mathrm{~m}^{2}\right)\end{array}$} & $\begin{array}{r}\geq 90 \\
60-89 \\
45-59 \\
30-44\end{array}$ & $\begin{array}{c}\text { Stage } 1 \\
\text { (pre-nephropathy) }\end{array}$ & $\begin{array}{c}\text { Stage } 2 \\
\text { (incipient nephropathy) }\end{array}$ & $\begin{array}{c}\text { Stage } 3 \\
\text { (overt nephropathy) }\end{array}$ \\
\hline & $\begin{array}{c}15-29 \\
<15\end{array}$ & \multicolumn{3}{|c|}{$\begin{array}{c}\text { Stage } 4 \\
\text { (kidney failure) }\end{array}$} \\
\hline & (dialysis therapy) & \multicolumn{3}{|c|}{$\begin{array}{c}\text { Stage } 5 \\
\text { (dialysis therapy) }\end{array}$} \\
\hline
\end{tabular}

\section{References}

1. Haneda M, Utsunomiya K, et al. On the Development of the Classification of Diabetic Nephropathy 2014 (Revised Classification of Diabetic Nephropathy). J Japan Diab Soc. 2014;57:529-34 (in Japanese).

2. Haneda M, Utsunomiya K, Koya D, et al. On the Development of the Classification of Diabetic Nephropathy 2014 (Revised Classification of Diabetic Nephropathy). Jpn J Nephrol. 2014;56:547-52 (in Japanese).

3. Haneda M, Utsunomiya K, Koya D, et al. On the Development of the Classification of Diabetic Nephropathy 2014 (Revised Classification of Diabetic Nephropathy). J Jpn Soc Dial Ther. 2014;47:415-9 (in Japanese).

4. Haneda M, Utsunomiya K, Koya D, et al. On the Development of the Classification of Diabetic Nephropathy 2014 (Revised Classification of Diabetic Nephropathy). Clin Nutr. 2014;17:325-30 (in Japanese).

5. Committee for Statistical Surveys, Japanese Society for Dialysis Therapy (JSDT): Current state of dialysis therapy in Japan, 2013 illustrated. http://docs.jsdt.or.jp/overview/index.html.

6. Diabetes survey research report. Ministry of Health and Welfare, Japan, 1991. p. 320.

7. Yoshikawa R. (principal investigator) Report of the Joint Committee on Diabetic Nephropathy. 1 On revision of the Ministry of Health, Labour and Welfare Version of the Classification of
Diabetic Nephropathy. J Japan Diab Soc. 2001;44:623 (in Japanese).

8. Guide to the management of chronic kidney disease (CKD). Jpn J Nephrol. 2007;49:767. (in Japanese).

9. Guide to the management of chronic kidney disease (CKD). 2012. Jpn J Nephrol. 2012;54:1047. (in Japanese).

10. Systematic research report from the Research Group of Diabetic Nephropathy, 2009-2012, Ministry of Health, Labour and Welfare, Japan, 2012. p. 1-28. http://mhlw-grants.niph.go.jp/.

11. Wada T, Haneda M, Furuichi K, Babazono T, Yokoyama H, Iseki K, Araki SI, Ninomiya T, Hara S, Suzuki Y, Iwano M, Kusano E, Moriya T, Satoh H, Nakamura H, Shimizu M, Toyama T, Hara A, Makino H, The Research Group of Diabetic Nephropathy, Ministry of Health, Labour and Welfare of Japan. Clinical impact of albuminuria and glomerular filtration rate on renal and cardiovascular events, and all-cause mortality in Japanese patients with type 2 diabetes. Clin Exp Nephrol. 2014;18:613-20.

12. Guidelines for lifestyle modification/diet therapy in patients with kidney disease. Jpn J Nephrol. 1997;39:1-37. (in Japanese).

13. Summary of revisions for the 2013 clinical practice recommendations. Diabetes Care. 2013;36 Suppl 1:S3. doi:10.2337/dc13S003.

14. Summary of revisions to the 2014 Clinical Practice Recommendations. Diabetes Care 2014;37 Suppl 1:S4. doi:10.2337/dc14S004. 